\title{
ANALISA USAHA BUDIDAYA IKAN LELE MASAMO (Clarias Gariepinus) KECAMATAN KEMBANGBAHU KABUPATEN LAMONGAN
}

\author{
Agung Pamuji Rahayu*, Muhammad Farid \\ *Fakultas Perikanan Universitas Islam Lamongan \\ Jl. Veteran No. 53 A Lamongan Phone /Fax 0322_324706
}

\begin{abstract}
ABSTRAK
Lele Masamo merupakan jenis lele yang pertumbuhannya lebih cepat, nafsu makannya tinggi, tahan terhadap penyakit, mudah beradaptasi dengan lingkungan yang baru, dan mampu bertahan di iklim yang ekstrim. Masyarakat di Desa Pelang Kecamatan Kembangbahu Kabupaten Lamongan Propinsi Jawa Timur sebagian besar bermata pencaharian sebagai petani tambak. Rata-rata jenis ikan yang dipilih untuk dibudidayakan adalah Lele Masamo. Lele Masamo merupakan produk baru yang dibudidayakan di Desa Pelang, sehingga analisa usahanya perlu diketahui. Penelitian dilakukan pada bulan Mei s.d. Juni 2017 dengan menggunakan 3 (tiga) kolam pembudidaya yang berbeda, masingmasing kolam berukuran $150 \mathrm{~m}^{2}, 175 \mathrm{~m}^{2}$, dan $150 \mathrm{~m}^{2}$ dan benih yang ditebar yaitu ikan Lele Masamo ukuran $7 \mathrm{~cm}$ dengan kepadatan 5000 ekor/kolam. Analisa usaha yang ingin diketahui yaitu jumlah besar biaya produksi, penerimaan dan keuntungan serta kelayakan usaha budidaya ikan Lele Masamo di Desa Pelang. Data yang mendukung hasil analisa usaha tersebut berdasarkan pengumpulan data primer meliputi komponen dari biaya perawatan, biaya pembuatan pakan, biaya operasional, biaya benih ikan, produksi dan harga jual. Pengumpulan data sekunder meliputi data yang dimiliki oleh pemilik budidaya, data kondisi sosial ekonomi wilayah setempat, teori dan hasil penelitian terkait dengan penelitian ini. Berdasarkan hasil penelitian rata-rata biaya produksi yang dikeluarkan pada usaha pembesaran ikan Lele Masamo dengan luas kolam 150 - $175 \mathrm{~m}^{2}$ sebesar Rp 9.657.000,-/panen s.d. Rp 10.142.000,-/panen dengan total penerimaan yang diterima sebesar Rp 12.487.500,-/panen s.d. Rp 13.095.000,-/panen dan besar keuntungan yang diterima sebesar Rp 2.345.500,-/panen s.d. Rp 3.235.500,/panen dan usaha pembesaran ikan Lele dalam kolam di Desa Pelang layak diusahakan dengan nilai R/C > 1, nilai BEP Produksi 715-733 ekor dan nilai BEP harga Rp10.112,- s.d. Rp10.964,-, serta hasil perhitungan FRR 23.13\% - 33.50\% bernilai lebih besar dari suku bunga Bank tahun 2017 yaitu $12.03 \%$ yang berarti sebaiknya dilakukan investasi pada usaha tersebut.
\end{abstract}

Kata Kunci : Lele Masamo, analisa usaha, budidaya

\section{PENDAHULUAN}

Ikan lele merupakan salah satu alternatif komoditas unggulan air tawar yang penting dalam rangka pemenuhan peningkatan gizi masyarakat (Natakesuma, 2016). Pesatnya perkembangan usaha budidaya ikan lele memberikan kontribusi yang sangat nyata terhadap peningkatan produksi perikanan budidaya. KKP (2011) dalam Nugroho (2015), mencatat bahwa produksi lele pada tahun 2011 sudah mendekati angka 350 ribu ton dengan percepatan pertumbuhan produksi per tahunnya mencapai $40 \%$.

Ikan Lele Masamo merupakan hasil pengembangan varian baru strain lele yang dilaksanakan oleh hatchery PT. Matahari Sakti di kota Mojokerto yang disebutkan salah satu induknya berasal dari Afrika, keunggulan 
diantaranya adalah cepat tumbuh dan relatif toleran terhadap fluktuasi lingkungan (Nugroho et. al., 2015, Abidin et. al., 2016). Pengembangan budidaya lele Masamo mulai berkembang di Lamongan seiring dengan meningkatnya permintaan pasar. Desa Pelang Kecamatan Kembangbahu Kabupaten Lamongan Propinsi Jawa Timur merupakan salah satu daerah yang mengembangkan budidaya ikan Lele produk baru ini. Kendala yang dialami dalam budidaya lele Masamo yaitu biaya pakan yang besar selama pembesaran hingga waktu panen. Hal tersebut menjadi perhatian khusus bagi pembudidaya di Desa Pelang karena keuntungan penjualan hasil panen yang diperoleh hampir tidak menutup pembiayaan pakannya.

Peneliti tertarik untuk mengetahui analisa usaha ikan Lele Masamo di Desa Pelang dengan mengetahui total biaya produksi, penerimaan dan keuntungan, dan menganalisis kelayakan usaha.

\section{METODOLOGI PENELITIAN}

Penelitian dilakukan pada bulan Mei s.d. Juni 2017 dengan menggunakan 3 (tiga) kolam pembudidaya yang berbeda, masing-masing kolam berukuran $150 \mathrm{~m}^{2}, 175 \mathrm{~m}^{2}$, dan $150 \mathrm{~m}^{2}$ dan benih yang ditebar yaitu ikan Lele Masamo ukuran 7 cm dengan kepadatan 5000 ekor/kolam. Analisa usaha yang ingin diketahui yaitu jumlah besar biaya produksi, penerimaan dan keuntungan serta kelayakan usaha.

Biaya Produksi adalah penjumlahan dari biaya tetap dan biaya tidak tetap dapat dituliskan dengan rumus :

$$
\mathbf{T C}=\mathbf{F C}+\mathrm{VC}
$$

Dimana :

TC : Biaya Total (Total Cost) (Rp/panen)

FC : Biaya Tetap (Fixed Cost) (Rp/panen)
VC : Biaya Tidak Tetap (Variable Cost) (Rp/panen)

(Sumber Pustaka : Tambunan et. al., 2017)

Penerimaan atau pendapatan kotor adalah jumlah uang atau nilai yang diperoleh dari hasil penjualan ikan Lele, dapat dituliskan dengan rumus :

$$
\mathbf{T R}=\mathbf{Q} \times \mathbf{P}
$$

Dimana :

TR : Total Penerimaan (Total Revenue) (Rp/panen)

Q : Produksi (Quantity) (Kg/panen)

$\mathrm{P} \quad$ : Harga (Price) (Rp)

(Sumber Pustaka : Tambunan et. al., 2017)

Keuntungan atau pendapatan bersih adalah selisih antara penerimaan dengan total biaya produksi yang dikeluarkan, dapat ditulis dengan rumus:

Dimana :

$$
\pi=\mathbf{T R}-\mathbf{T C}
$$

$\pi \quad$ : Keuntungan (Rp/panen)

TR : Total Penerimaan (Total Revenue) (Rp/panen)

TC : Biaya Total (Total Cost) (Rp/panen) (Sumber Pustaka : Tambunan et. al., 2017) Menganalisis kelayakan usaha pembesaran ikan Lele Masamo, analisis data yang digunakan adalah menurut Umar (2009), Effendi dan Oktariza (2006), Sugiarto et. al., (2002) dalam Rosalina (2014), beberapa metode yang biasa dipertimbangkan dalam penilaian aliran kas dari suatu investasi yaitu salah satunya adalah Revenue Cost Ratio (R/C) dan Break Even Point (BEP) :

$$
\text { Revenue Cost Ratio }(\mathrm{R} / \mathrm{C})=\frac{\mathrm{TR}}{\mathrm{TC}}
$$

Dimana:

$\mathrm{TR}=$ total revenue (total penerimaan)

$\mathrm{TC}=$ total cost (total pengeluaran)

Menurut Rahardi et. al. (2004), Revenue Cost Ratio (R/C) adalah perbandingan total 
penerimaan yang diperoleh dengan total biaya yang dikeluarkan

\section{$\mathrm{R} / \mathrm{C}>1$ : Menguntungkan \\ $\mathrm{R} / \mathrm{C}=1$ : Tidak untung / rugi \\ R/C $<1$ : Rugi}

Menurut Suhardi (2016) Break Even Point (BEP) atau titik impas adalah suatu analisis untuk menentukan dan mencari jumlah barang atau jasa yang harus dijual kepada konsumen pada harga tertentu untuk menutupi biaya-biaya yang timbul serta mendapatkan keuntungan/ profit.

Menurut Sunyoto (2013) dalam Suhardi (2016), analisis BEP merupakan teknik analisis yang ditunjukkan untuk menghasilkan informasi dan dengan memusatkan perhatian pada penentuan suatu keadaan dimana volume kegiatan (yang diukur dengan hasil penjualan) tidak menghasilkan laba tetapi juga tidak mengalami kerugian.

$$
\text { TR = TC atau Q.P }=\mathbf{a}+\mathbf{b} . \mathbf{X}
$$

Di mana :

$\mathrm{Q}=$ tingkat produksi (unit)

$\mathrm{P}=$ harga jual per unit

$\mathrm{X}=$ luas produksi

$\mathrm{a}=$ biaya tetap

$\mathrm{b}=$ biaya variabel

atau BEP dapat dituliskan dalam bentuk produksi dan harga dengan persamaan :

BEP produksi $=\frac{\text { Total Biaya }}{\text { Harga Penjualan }}$

\section{Atau}

BEP harga $=\frac{\text { Total Biaya }}{\text { Total produksi }}$
Menurut Tambunan (2017), analisis Financial Rate of Return (FRR) merupakan persentase perbandingan keuntungan dengan total investasi yang ditanamkan. Analisis ini digunakan untuk mengetahui efesiensi penggunaan modal usaha, dapat ditulis dengan rumus :

Dimana :

$$
\mathrm{FRR}=\pi / \mathrm{TI} * 100 \%
$$

FRR : Financial Rate of Return

$\pi \quad$ : Keuntungan (Rp/panen)

TI : Total Investasi (Rp/panen)

Kriteria keputusan :

FRR>suku bunga Bank, maka sebaiknya dilakukan investasi pada usaha tersebut.

FRR<suku bunga Bank, maka sebaiknya tidak dilakukan investasi pada usaha tersebut.

Data yang mendukung hasil analisa usaha tersebut berdasarkan pengumpulan data primer meliputi komponen dari biaya perawatan, biaya pembuatan pakan, biaya operasional, biaya benih ikan, produksi dan harga jual. Pengumpulan data sekunder meliputi data yang dimiliki oleh pemilik budidaya, data kondisi sosial ekonomi wilayah setempat, teori dan hasil penelitian terkait dengan penelitian ini.

\section{HASIL DAN PEMBAHASAN}

Biaya Produksi dapat diketahui dengan penjumlahan modal tetap dan biaya tidak tetap. Dimana modal tetap dan biaya tidak tetap yang digunakan pembudidaya sangat mempengaruhi produksi pada usaha yang dijalankan, tergantung dari luas kolam yang dimiliki oleh masingmasing pembudidaya (Tabel 1). 
Tabel 1. Biaya Produksi Budidaya Ikan Lele Masamo Desa pelang Kecamatan Kembangbahu Kabupaten Lamongan

\begin{tabular}{cccrr}
\hline Pembudidaya & $\begin{array}{c}\text { Luas Kolam } \\
\left(\mathbf{m}^{2}\right)\end{array}$ & $\begin{array}{c}\text { Modal Tetap } \\
(\mathbf{R} \mathbf{p})\end{array}$ & $\begin{array}{c}\text { Modal Tidak } \\
\text { Tetap }(\mathbf{R} \mathbf{p})\end{array}$ & $\begin{array}{c}\text { Biaya Produksi } \\
(\mathbf{R p})\end{array}$ \\
\hline 1 & 150 & 3.117 .000 & 6.785 .000 & 9.902 .000 \\
2 & 175 & 3.622 .000 & 6.520 .000 & 10.142 .000 \\
3 & 150 & 3.155 .000 & 6.502 .000 & 9.657 .000 \\
\hline
\end{tabular}

Harga jual ikan Lele Masamo dengan ukuran 7-9 pembudidaya $\quad$ yaitu $\quad$ Rp.12.487.500 $\quad$ s.d. ekor per Kg berkisar Rp.13.500,-. Hasil Rp.13.095.000 (Tabel 2) perhitungan penerimaan masing-masing

Tabel 2. Penerimaan Budidaya Ikan Lele Masamo Desa pelang Kecamatan Kembangbahu Kabupaten Lamongan

\begin{tabular}{cccc} 
Pembudidaya & Produksi $(\mathbf{K g})$ & Harga $(\mathbf{R p})$ & Penerimaan $(\mathbf{R p})$ \\
\hline 1 & 970 & 13.500 & 13.095 .000 \\
2 & 925 & 13.500 & 12.487 .500 \\
3 & 955 & 13.500 & 12.892 .500 \\
\hline
\end{tabular}

Tabel 3. Keuntungan Budidaya Ikan Lele Masamo Desa pelang Kecamatan Kembangbahu Kabupaten Lamongan

\begin{tabular}{crrr}
\hline Pembudidaya & Penerimaan $($ Rp) & Biaya Produksi (Rp) & Keuntungan (Rp) \\
\hline 1 & 13.095 .000 & 9.902 .000 & 3.193 .000 \\
2 & 12.487 .500 & 10.142 .000 & 2.345 .500 \\
3 & 12.892 .500 & 9.657 .000 & 3.235 .500 \\
\hline
\end{tabular}

Hasil keuntungan terbesar yaitu pada $\mathrm{R} / \mathrm{C}>1:$ Menguntungkan Pembudidaya 3 Rp. 3.235.500,-sebaliknya yang $\mathrm{R} / \mathrm{C}=1$ : Tidak untung / rugi terkecil yaitu pada Pembudidaya 2 Rp. R/C $<1$ : Rugi

\subsubsection{0,- (Tabel 3).}

Menurut Rahardi et. al., (2004), Revenue Cost Ratio (R/C) adalah perbandingan total penerimaan yang diperoleh dengan total biaya yang dikeluarkan
Analisis data berdasarkan perhitungan Revenue Cost Ratio (R/C) menghasilkan nilai lebih dari 1 yang berarti usaha budidaya ikan Lele Masamo ini menguntungkan dan layak untuk diusahakan (Tabel.4).

Tabel 4. Revenue Cost Ratio (R/C) Budidaya Ikan Lele Masamo Desa pelang Kecamatan Kembangbahu Kabupaten Lamongan

\begin{tabular}{crrr}
\hline Pembudidaya & Penerimaan $(\mathbf{R p})$ & Biaya Produksi $(\mathbf{R p})$ & \multicolumn{1}{c}{ R/C } \\
\hline 1 & 13.095 .000 & 9.902 .000 & 1,32 \\
2 & 12.487 .500 & 10.142 .000 & 1,23 \\
3 & 12.892 .500 & 9.657 .000 & 1,34 \\
\hline
\end{tabular}


Menurut Sunyoto (2013) dalam Suhardi (2016), analisis BEP merupakan teknik analisis yang ditunjukkan untuk menghasilkan informasi dan dengan memusatkan perhatian pada penentuan suatu keadaan dimana volume kegiatan (yang diukur dengan hasil penjualan) tidak menghasilkan laba tetapi juga tidak mengalami kerugian. Hasil perhitungan BEP Produksi terlihat kisaran jumlah produksi ikan Lele Masamo yang diperlukan untuk nilai impas yaitu 715 s.d. 751 (Tabel 5). Hasil perhitungan BEP Harga terlihat kisaran harga yang dapat ditentukan untuk nilai impas yaitu Rp. 10.112,-s.d.Rp.10.964,-(Tabel.6).

Tabel 5. Break Even Point (BEP) Produksi Budidaya Ikan Lele Masamo Desa Pelang Kecamatan Kembangbahu Kabupaten Lamongan

\begin{tabular}{crrr}
\hline Pembudidaya & Biaya Produksi (Rp) & Harga (Rp) & BEP Produksi \\
\hline 1 & 9.902 .000 & 13.500 & 733 \\
2 & 10.142 .000 & 13.500 & 751 \\
3 & 9.657 .000 & 13.500 & 715 \\
\hline
\end{tabular}

Tabel 6. Break Even Point (BEP) Harga Budidaya Ikan Lele Masamo Desa pelang Kecamatan Kembangbahu Kabupaten Lamongan

\begin{tabular}{crcr}
\hline Pembudidaya & Biaya Produksi $(\mathbf{R p})$ & Produksi $($ Kg) & BEP Harga \\
\hline 1 & 9.902 .000 & 970 & 10.208 \\
2 & 10.142 .000 & 925 & 10.964 \\
3 & 9.657 .000 & 955 & 10.112 \\
\hline
\end{tabular}

Menurut Tambunan (2017), analisis Financial 12.03\% (Setiawan, 2017). Hasil perhitungan FRR Rate of Return (FRR) merupakan persentase yaitu 23.13\%-33.50\% yang berarti lebih besar perbandingan keuntungan dengan total investasi dari nilai suku bunga Bank 12.03\%, maka yang ditanamkan. Bank Indonesia melaporkan sebaiknya dilakukan investasi pada usaha bahwa suku bunga Bank per Januari 2017 yaitu budidaya ikan Lele Masamo tersebut (Tabel 7).

Tabel 7. Financial Rate of Return (FRR) Budidaya Ikan Lele Masamo Desa Pelang Kecamatan Kembangbahu Kabupaten Lamongan

\begin{tabular}{crrr}
\hline Pembudidaya & Keuntungan $(\mathbf{R p})$ & Biaya Produksi $(\mathbf{R p})$ & \multicolumn{1}{c}{ FRR } \\
\hline 1 & 3.193 .000 & 9.902 .000 & 32,25 \\
2 & 2.345 .500 & 10.142 .000 & 23,13 \\
3 & 3.235 .500 & 9.657 .000 & 33,50 \\
\hline
\end{tabular}

\section{KESIMPULAN}

Kesimpulan yang didapat berdasarkan hasil penelitian rata-rata biaya produksi yang dikeluarkan pada usaha pembesaran ikan Lele Masamo dengan luas kolam 150 - $175 \mathrm{~m}^{2}$ sebesar Rp 9.657.000,-/panen s.d. Rp 10.142.000,-/panen dengan total penerimaan yang diterima sebesar Rp 12.487.500,-/panen s.d. Rp 13.095.000,/panen dan besar keuntungan yang diterima sebesar Rp 2.345.500,-/panen s.d. Rp 3.235.500,/panen dan usaha pembesaran ikan Lele dalam kolam di Desa Pelang layak 
diusahakan dengan nilai $\mathrm{R} / \mathrm{C}>1$, nilai $\mathrm{BEP}$ Produksi 715-733 ekor dan nilai BEP harga Rp10.112,- $\quad$ s.d. Rp10.964,-, serta hasil perhitungan FRR $23.13 \%$ - $33.50 \%$ bernilai lebih besar dari suku bunga Bank tahun 2017 yaitu $12.03 \%$ yang berarti sebaiknya dilakukan investasi pada usaha tersebut.

\section{DAFTAR PUSTAKA}

Abidin, Z., Wahyu, H., Mochammad, F. 2016. Analysis of Masamo Catfish Marketing by Analytical Approach at Farmer Group "Sumber Lancar", Blimbing, Malang City. Economic and Social of Fisheries and Marine Journal 04(01): 90-104.

Natakesuma, I. 2016. Analisis Produksi dan Finansial Usaha Budidaya Ikan Lele di Kota Metro. Tesis. Universitas Lampung. Bandar Lampung.

Nugroho, E., Sabara, P., Mohammad, A.S., Lalu, M., Sigit, B., Zulkifli. 2015. Efek Heterosis dari Hibrida Ikan Lele Unggul di Nusa Tenggara Barat. Jurnal Riset Akuakultur 10(1):33-40.

Rahardi, F., Kristiawati, R., Nazaruddin. 2004. Agribisnis Perikanan. Penebar Swadaya: Jakarta.

Rosalina, D. 2014. Analisis Kelayakan Usaha Budidaya Ikan Lele di Kolam Terpal di Desa Namang Kabupaten Bangka Tengah. Maspari Journal 6 (1): 20-24.

Setiawan, S. R. D. 2017. Bank Indonesia: Januari 2017, Suku Bunga Kredit 12.03 Persen. https://ekonomi.kompas.com/read/2017 /03/01/113000526/bank.indonesia.janua ri.2017.suku.bunga.kredit.12.03.persen.

Suhardi, M. 2016. Analisis Break ven Point (BEP) Usaha Ikan Asin di Desa Tanjung Aru Kecamatan Tanjung Harapan Kabupaten Paser. Jurnal Administrasi Bisnis 4(1):142-156.

Tambunan, S., Yulianti, S., Eni, Y., Lamun, B. 2017. The Business Analysis of Catfish (Clarias sp) Enlargement on Fish Pond In Sub-District of Minas, District of Siak, Riau Province. JOM 4(1):1-15. 